\title{
Region-Wide Comprehensive Implementation of Roguing Infected Trees, Tree Replacement, and Insecticide Applications Successfully Controls Citrus Huanglongbing
}

\author{
Xiaoyong Yuan, ${ }^{1}$ Cixiang Chen, ${ }^{2}$ Renato Beozzo Bassanezi, ${ }^{3}$ Feng Wu, ${ }^{4}$ Zheng Feng, ${ }^{5}$ Damin Shi, ${ }^{1}$ Jinyun Li, ${ }^{6}$ Yimin Du, ${ }^{1}$ \\ Ling Zhong, ${ }^{7}$ Balian Zhong, ${ }^{8}$ Zhanjun Lu, ${ }^{8}$ Xiang Song, ${ }_{1}^{1}$ Yan Hu, ${ }^{2}$ Zhigang Ouyang, ${ }_{1}^{1}$ Xinjun Liu, ${ }_{1}$ Jinzhao Xie, ${ }^{2}$ Xi Rao, \\ Xi Wang, ${ }^{7}$ Dapeng Oliver Wu, ${ }^{5}$ Zhengfei Guan, ${ }^{4}$ and Nian Wang ${ }^{6, \dagger}$ \\ ${ }^{1}$ Citrus Huanglongbing Joint Laboratory, National Navel Orange Engineering Research Center, Gannan Normal University, Ganzhou, Jiangxi, \\ China \\ ${ }^{2}$ Ganzhou Plant Protection Department of Fruit Industry/Jiangxi Navel Orange Engineering Research Center, Ganzhou, Jiangxi, China \\ ${ }^{3}$ Department of Research and Development, Fundecitrus, Araraquara, SP, Brazil \\ ${ }_{5}^{4}$ Gulf Coast Research and Education Center, University of Florida, Wimauma, FL, U.S.A. \\ ${ }_{6}^{5}$ Department of Electrical \& Computer Engineering, University of Florida, Gainesville, FL, U.S.A. \\ ${ }^{6}$ Citrus Research and Education Center, Department of Microbiology and Cell Science, Institute of Food and Agricultural Sciences, University \\ of Florida, Lake Alfred, FL, U.S.A. \\ ${ }^{7}$ Plant Protection Bureau, Department of Agriculture, Nanchang, Jiangxi, China \\ ${ }^{8}$ National Navel Orange Engineering Research Center, Gannan Normal University, Ganzhou, Jiangxi, China \\ Accepted for publication 21 December 2020.
}

\begin{abstract}
Huanglongbing (HLB) is a devastating citrus disease worldwide. A three-pronged approach to controlling HLB has been suggested, namely, removal of HLB-symptomatic trees, psyllid control, and replacement with HLB-free trees. However, such a strategy did not lead to successful HLB control in many citrus-producing regions, such as Florida. We hypothesize that this is because of the small-scale or incomprehensive implementation of the program; conversely, a comprehensive implementation of such a strategy at the regional level can successfully control HLB. To test our hypothesis, we investigated the effects of region-wide comprehensive implementation of this scheme to control HLB in Gannan region, China, with a total planted citrus acreage of over 110,000 ha from 2013 to 2019. With the region-wide implementation of comprehensive HLB management, the overall HLB incidence in Gannan decreased from $19.71 \%$ in 2014 to $3.86 \%$ in 2019 . A partial implementation of such a program (without a comprehensive inoculum removal) at the regional level in Brazil resulted in HLB incidence increasing from $1.89 \%$ in 2010 to $19.02 \%$ in
\end{abstract}

ABSTRACT
2019. Using dynamic regression model analyses with data from both Brazil and China, we constructed a model to predict HLB incidence when all three components were applied at $100 \%$. It was predicated that in a region-wide comprehensive implementation of such a program, HLB incidence would be controlled to a level of less than $1 \%$. We conducted economic feasibility analyses and showed that average net profits were positive for groves that implemented the comprehensive strategy, but groves that did not implement it had negative net profits over a 10-year period. Overall, the key for the three-pronged program to successfully control HLB is the large scale (region-wide) and comprehensiveness in implementation. This study provides valuable information to control HLB and other economically important endemic diseases worldwide.

Keywords: Asian citrus psyllid, bacterial pathogens, citrus, Diaphorina citri, disease control and pest management, economic analysis, greening, huanglongbing, pesticide, three-pronged
Citrus huanglongbing (HLB, also called citrus greening) is caused by Candidatus Liberibacter spp. (Bové 2006). HLB is endemic in most citrus-producing countries and is considered the most

${ }^{\dagger}$ Corresponding author: N. Wang; nianwang@ufl.edu

X. Yuan, C. Chen, R. Bassanezi, F. Wu, Z. Feng, and D. Shi contributed equally to this work.

Funding: This study has been supported by Florida Citrus Initiative Program, Citrus Research and Development Foundation, U.S. Department of Agriculture National Institute of Food and Agriculture grants 2018-70016-27412 and 201670016-24833 (N. Wang), The Major Science and Technology R\&D Program of Jiangxi Province, and The National Key R\&D Program of China (B. Zhong, Z. Lu, Z. Ouyang, and C. Chen).

*The $\boldsymbol{e}$-Xtra logo stands for "electronic extra" and indicates that one supplementary table is published online.

The author(s) declare no conflict of interest.

(cc)(i) $\ominus$ Copyright (c) 2021 The Author(s). This is an open access article cc. devastating citrus disease worldwide (Hodges et al. 2014; Li et al. 2020; Singerman and Rogers 2020). Candidatus Liberibacter spp. colonize the phloem of trees and are transmitted by the Asian and African citrus psyllids (ACPs) Diaphorina citri and Trioza erytreae, respectively (Bové 2006). The predominant HLB pathogen worldwide is ' $\mathrm{Ca}$. L. asiaticus' (CLas), which originated in Asia (Bové 2006) and has spread to most major citrus-producing countries except the Mediterranean Basin and Australia (Wang 2020). The spread of HLB has been facilitated by the rapid expansion of ACPs to new territories (Shimwela et al. 2016). Furthermore, all commercial citrus varieties are susceptible to HLB (Folimonova et al. 2009; McCollum et al. 2016). Controlling HLB is the most daunting challenge for citrus growers in the HLB-endemic regions despite numerous advances in different aspects of the HLB pathosystem, including controlling ACP (Boina et al. 2010; Stansly et al. 2014), understanding the virulence mechanism of CLas (Pang et al. 2020; Thapa et al. 2020), treating HLB-diseased trees with horticultural approaches (Canales et al. 2016; Gottwald et al. 2012; Li et al. 2016, 2017, 2019a) and antimicrobials (Akula et al. 2011; Hu and Wang 2016; Hussain et al. 2019; Li et al. 2019b, 2021), improving CLas detection (Gottwald et al. 
2020; Kim and Wang 2009), and developing tolerant or resistant citrus varieties using traditional and novel genome editing approaches (Deng et al. 2019; Jia and Wang 2014, 2020; Jia et al. 2017, 2019).

A three-pronged strategy, consisting of removal of HLBsymptomatic trees, ACP control with pesticides, and replacement with HLB-free citrus trees, has been proposed to be key to managing citrus HLB (Bové 2006; Chiyaka et al. 2012; Gottwald 2010; Zheng et al. 2018). This comprehensive program targets critical components of the HLB pathosystem (Wang et al. 2017a, b). Small-scale trials of this approach have shown inconsistent effect for HLB management (Bassanezi et al. 2013; Chiyaka et al. 2012; Gottwald 2010). Implementation of this approach was conducted in a UNDP-FAO Citrus Rehabilitation Project in Southeast Asia in the mid-1980s (Gottwald and McCollum 2017). However, the effectiveness of long-term, region-wide implementation has not been reported previously. Furthermore, there has been debate over the likely effectiveness of the strategy (Chiyaka et al. 2012). In Florida, after HLB was first identified in 2005, these HLB management approaches were implemented by many citrus growers, such as Southern Garden and Citrus Producers Inc., but not by the majority of citrus growers in South and central Florida (Halbert 2005; Shimwela et al. 2018). Most of the citrus growers that were removing HLB-symptomatic trees stopped doing so due to high disease incidence by 2009. Furthermore, tree removal was never implemented statewide (Graham et al. 2020); instead, most growers chose to rely on ACP control and to plant HLB-free trees. Although HLB spread was slower in counties with large groves where all three HLB management approaches were applied (Shimwela et al. 2018), HLB continued to spread throughout Florida, resulting in all groves being infected by 2013, with nearly all mature citrus trees in groves being infected by CLas (Graham et al. 2020).

We hypothesize that limited effect of the three-pronged program on HLB control is because of the small-scale or incomprehensive implementation of the program. HLB endemic in the citrus-producing countries can be classified into three levels based on the frequency of ACP immigration and transmission of CLas between the constituents: local (groves closely next to each other), area-wide (groves in an area, such as within a county, that might be with clear separation between groves, but the separation is not enough to prevent psyllids dispersal between groves within days), and regional (groves in a much larger area, such as at state or province level or near such a scale, with long distance, geographical separation or barriers preventing ACP from dispersing to another region en masse frequently) (Wang et al. 2017a, b). Intriguingly, the three-pronged program was applied mostly at local or area-wide levels, such as that conducted by citrus growers in South and central Florida (Graham et al. 2020).

We hypothesize that a comprehensive implementation of removal of HLB-symptomatic trees, ACP control with pesticides, and replacement with HLB-free citrus trees at the regional level can successfully control HLB. The specific objectives of this study are to investigate the HLB control efficacy of region-wide comprehensive implementation of the three-pronged strategy; to predict the outcome of such a strategy in controlling HLB via modeling; and to analyze the economic feasibility of such a program. Here, we investigated the effectiveness of region-wide implementation of such a comprehensive HLB control strategy in Gannan region, Jiangxi Province, China, over 7 years (2012 to 2019). Gannan is the largest navel sweet orange-producing region in the world, with a total planted acreage of approximately 119,000 ha. Large numbers of ACPs and HLBsymptomatic trees were observed in citrus groves in Gannan in 2012, followed by reports of high incidence of HLB in 2013. Region-wide implementation of the comprehensive HLB management program was launched in late 2012 and continued to date. Because of the scale of the implementation, there are no suitable controls. As a compromise, we compared the HLB control effect in Gannan with that in Brazil, where HLB was first observed in 2004 (Teixeira et al. 2005) and such a strategy was partially implemented (Bassanezi et al. 2020). The successful example of HLB management presented in this study provides valuable information to control HLB in other citrus-producing regions and to control other economically important endemic diseases worldwide.

\section{MATERIALS AND METHODS}

Comprehensive HLB management in Gannan, Jiangxi Province, China. In Gannan, the comprehensive HLB management program included the following measures. First, diseased-tree removal. The removal of HLB-symptomatic trees was performed by the Ganzhou Plant Protection Department of Fruit Industry together with extension personnel and citrus growers immediately after an annual region-wide survey (see below). For tree removal, a five-step method was adopted to cut and clean the diseased trees, as follows: sawing the diseased tree, marking the remaining stump, treating the stump with glyphosate following the manufacturer's recommendations to prevent young flush, wrapping the stump with a black plastic bag, and covering the stump with soil. Of note is that all trees in a grove with an HLB incidence greater than $30 \%$ were removed. Second, psyllid control. Most citrus growers in Gannan have small size farms ( $<20 \mathrm{ha})$ and manage their groves individually under guidance from extension personnel. Although there are thousands of citrus growers in Gannan, each operating independently of the others, pesticide applications were rather comprehensive and made at high frequency, and very few groves are without psyllid control, which has a region-wide effect on psyllid control. Third, replacement. Removed trees were replaced with HLB-free healthy citrus trees. The replacement trees were planted in screenhouses next to the groves and grown for 1 to 2 years before transplantation to groves to speed up production and overcome the long juvenile period. To avoid the negative effects of pots on root growth, 1-year-old trees were grown in growth bags containing $15 \mathrm{~kg} / \mathrm{bag}$ of soil with organic fertilizer and replanted into bags containing $30 \mathrm{~kg} / \mathrm{bag}$ of soil after 1 year in the screenhouse. Over-fertilization of the potted plants was avoided, and instead, fertilization was conducted in small doses every 10 to 15 days. Irrigation was conducted as needed to keep the soil moist. The young trees were approximately $0.7 \mathrm{~cm}$ in stem diameter and $50 \mathrm{~cm}$ tall, but they averaged 2 and $3.5 \mathrm{~cm}$ in stem diameter and 120 and $160 \mathrm{~cm}$ tall after 1 and 2 years in the screenhouse, respectively.

Comprehensive HLB management in the Brazilian citrus belt. In the São Paulo and Triângulo/Sudoeste Mineiro citrus belt, a comprehensive HLB management scheme, similar to that of Gannan (but without replacement with large trees), was employed in 2005 to 2010. Starting in 2005, the removal of HLBsymptomatic trees was mandatory and reinforced by the phytosanitary agents of São Paulo State. Fundecitrus organized inspections of HLBsymptomatic trees and notified the growers to remove them. However, the mandatory removal of HLB-symptomatic trees was stopped in 2010. The removal of HLB-symptomatic trees was then left to the growers, and many growers decided not to remove trees, particularly adult trees. For tree replacement, in citrus groves that were less than 8 years old, when an HLB-positive tree was removed, a healthy tree was usually planted in the same place (depending on the original spacing between trees in the row, the reset could be with two new trees). For groves that were more than 8 years old, there was no replacement with new trees in the place of the removed tree. Instead, when the number of removed trees or HLB incidence became high and compromised the economic productivity of the citrus block $(<800$ boxes per hectare), the trees of the entire block were removed and a new solid block was planted.

Investigation of HLB incidence in Gannan, Jiangxi Province, China. The incidence of HLB was assessed for every tree in all citrus groves by visual observation of typical HLB symptoms each October to December between 2013 and 2019. The symptoms used for HLB identification included leaf symptoms (e.g., blotchy mottle) and discolored fruit (e.g., red-nosed). Investigation of the overall HLB incidence in Gannan from 2013 to 2019 was 
organized by the Ganzhou Plant Protection Department of Fruit Industry together with extension personnel and citrus growers. All HLB-symptomatic trees were marked for removal after the HLBincidence survey, as described above.

Investigation of HLB incidence in the São Paulo and Triângulo/Sudoeste Mineiro citrus belt, Brazil. The Brazilian citrus belt is divided into 12 regions according to location and climate: Triângulo Mineiro, Bebedouro, Altinópolis, Votuporanga, São José do Rio Preto, Matão, Duartina, Brotas, Porto Ferreira, Limeira, Avaré e Itapetininga. Surveys were carried out in these areas annually, from April to July, which are autumn and winter in Brazil (preharvest time), when the symptoms of HLB are obvious and easier to detect by visual inspection. The HLB survey was conducted by a team of inspectors trained to recognize HLB symptoms by Fundecitrus. HLB incidence was investigated from 2009 to 2020, except in 2013 and 2014. For each survey, approximately 2,200 blocks, representing $5 \%$ of the total citrus blocks in the citrus belt, were assessed, including the main sweet orange varieties (Hamlin, Westin, Rubi, Valencia Americana, Seleta, Pineapple, Pera Rio, Valencia, Natal, and Valencia Folha Murcha).

The selection of the sampled citrus blocks was done by lot, using a proportional stratified sampling technique, in which the number of samples in each stratum combination (region/farm size/citrus age) was proportional to the number of trees in each stratum combination.

The 2,200 citrus blocks were stratified into 12 regions, four groups of farm size, and four groups of citrus age. The four farm sizes were up to 10,000 trees, 10,001 to 100,000 trees, 100,001 to 200,000 trees, and above 200,000 trees. The four tree ages were 0 to 2 years old, 3 to 5 years old, 6 to 10 years old, and more than 10 years old.

In each selected block, 11 trees were inspected for HLB symptoms. These were usually the 15 th to the 25 th trees in one row (varying from the 10th to 15 th row in each year). In this way, over $80 \%$ of inspected trees were located from $20 \mathrm{~m}$ to $80 \mathrm{~m}$ from the edge of the block. This design allowed less sampling to occur at the edge of block $(<15 \%)$ to avoid the edge effect and produce an overestimation of HLB incidence (Gottwald 2010) but without too much sampling in the block center $(<5 \%)$ to avoid an underestimation of HLB incidence. After the visual surveys, $10 \%$ of inspected trees were selected for further confirmation using a PCR test for CLas or ' $\mathrm{Ca}$. L. americanus' detection (Bassanezi et al. 2020). For the entire citrus belt, approximately 24,200 trees were observed in each survey, and HLB incidence was estimated for the entire citrus belt region and not for individual groves. Using this methodology, an error of $\pm 4 \%$ was estimated for citrus belt mean HLB incidence, within the $95 \%$ confidence interval.

Case study of groves using a representative insecticide program for ACP control in Gannan. A total of 30 citrus groves used an ACP control program designed by Shi, a member of our collaboration team (Supplementary Table S1; Table 1), hereafter referred to as the Shi Program. Other groves in Gannan used similar pesticides but with slightly different frequencies and schedules. The 30 groves also removed HLB-symptomatic trees with replacement, as described above. We used those groves to compare the control effects of the three-pronged program on HLB management at the grove level. For this purpose, we identified three groves that did not conduct comprehensive HLB management (Table 1). Of note, it was difficult to identify groves that did not conduct the comprehensive HLB management. In addition, we surveyed four groves that conducted removal of HLB-symptomatic trees and replacement but used a different insecticide program from the Shi Program (Table 1).

When possible, we also collected the following information: total number of trees per grove, number of trees removed per grove and year, total fruit yield per grove, yield per tree, price, and production cost, including pesticides, fertilizers, and labor.

To compare HLB incidence among the three groups mentioned above, approximately $20 \%$ of the trees of each grove were assessed for HLB symptoms by investigating multiple rows in fall 2019. The first two rows next to the edge were not selected to avoid overestimation. For confirmation purposes, approximately 10 symptomatic trees per grove were tested for CLas using qPCR, as described elsewhere (Wang et al. 2006).

Dynamic regression model analyses. Using the application rates for the comprehensive strategy and the corresponding incidence of HLB in Gannan, China (Table 2) and the São Paulo and Triângulo/ Sudoeste Mineiro citrus belt, Brazil (Table 3), and a forecasting model was built to predict the incidence of HLB when the scheme was conducted at $100 \%$ for each component. With the data from both Brazil and China, we formulated a linear dynamic regression model. This model allows the inclusion of relevant information from the predictor variables of the components of the strategy and information from past observations. Because components 1 (psyllid control) and 2 (replacement with HLB-free trees) were fully implemented in both Brazil and China during the study period, only component 3 (removal of diseased trees), which showed variation over years, was included in the model. Therefore, we defined a regression model as follows:

$$
y_{t}=\beta_{0}+\beta_{1} y_{t-1}+\beta_{2} x_{1, t}+\beta_{3} x_{2, t}+\varepsilon_{t}
$$

where $y_{t}$ is disease incidence at time $t, x_{1, t}$ is the predictor variable of component 3 at time $t, x_{2, t}$ is a dummy variable that takes the value of 1 for observations in Brazil and 0 for observations in China, $\beta$ is the model coefficient, and $\varepsilon_{t}$ is the error term.

Nonlinear regression analyses. Nonlinear regress analyses were conducted to verify the predictions based on dynamic regression analyses. The effects of the comprehensive disease control scheme on HLB incidence in groves in Gannan, China (Table 2) were more consistent than those in Brazil (Table 3). Therefore, a forecasting model was built to predict HLB incidence when the scheme was conducted at $100 \%$ for each component, based on data from Gannan (Table 2). A nonlinear regression model with a Gompertz function, describing growth over time, was formulated as follows:

$$
y_{t}=100 \times a \times(1-\exp (-b \times \exp (-r t)))
$$

where $y_{t}$ is the HLB disease incidence at time $t, a$ is a parameter related to the initial HLB incidence, $b$ is a parameter related to disease control efficacy, $r$ is the annual progress rate of CLas-positive trees, and $t$ is the time in years ( $t=0$ for 2014). The analyses were conducted using the NLIN procedure in SAS V9.4 (SAS Institute Inc., Cary, NC).

Economic feasibility analyses. The whole farm budgeting method was used to describe the financial information of the entire grove business. We calculated the level of economic performance (e.g., profit) of the entire operation for citrus groves to assess whether the comprehensive strategy would make the operation economically sustainable. We also compared profitability between implementing and not implementing the comprehensive strategy to identify which would be more cost-effective. The profit was calculated using gross revenue minus all of the costs incurred in citrus production. The cost budget accounts for all expense categories to estimate the total cost of production. In the analyses, the labor costs of removing and replacing trees, the cost of HLB-free trees, the cost of using the Shi Program, and other production costs (e.g., fertilizer and harvesting) were analyzed to estimate the total cost of citrus production. We focused on the data that were available from Gannan for groves with different operations. For each grove, the average net profit (dollars per tree) over years was estimated and compared.

\section{RESULTS}

Effects of the three-pronged program on HLB control in Gannan, China. In the early stages of the implementation of the three-pronged program in Gannan (2012 to 2015), the overall incidence of HLB in the Gannan region was $10.82,19.71$, and $7.85 \%$ in 2013 , 2014, and 2015, respectively (Fig. 1, Table 2). The increase in HLB 
incidence from 2013 to 2014 was likely due to the lack of comprehensive implementation of the three-pronged system in 2013 and the incubation period (time between pathogen infection and symptom expression) needed for HLB symptom development. It was reported that HLB symptoms take months or years to be visible after ACP transmission (Gottwald 2010; Shen et al. 2013a), probably because of the density of ACPs and the titers of CLas in ACPs. With the comprehensive implementation of the HLB control program in 2016, overall HLB incidence in the Gannan region was reduced to $7.21,4.62,4.36$, and $3.86 \%$ in $2016,2017,2018$, and 2019, respectively (Fig. 1, Table 2).

The total navel orange acreage in Gannan decreased from 118.75 kha in 2012 to 102.89 Kha in 2017 , the lowest amount, but it increased to 108.7 kha in 2019 (Table 2). The total yield declined from 1.25 million

TABLE 1. Incidence of huanglongbing (HLB) in citrus groves conducting the three-pronged HLB management in Gannan, Jiangxi Province, China ${ }^{\mathrm{a}}$

\begin{tabular}{|c|c|c|c|c|c|c|c|c|c|c|c|c|}
\hline \multirow[b]{2}{*}{ County } & \multirow[b]{2}{*}{ Groves } & \multirow{2}{*}{$\begin{array}{c}\text { Planting } \\
\text { time }\end{array}$} & \multirow{2}{*}{$\begin{array}{c}\text { Acreage } \\
\text { (ha) }\end{array}$} & \multicolumn{7}{|c|}{ HLB incidence $(\%)$} & \multirow[b]{2}{*}{ Three-pronged } & \multirow{2}{*}{$\begin{array}{c}\text { Shi } \\
\text { Program }\end{array}$} \\
\hline & & & & 2013 & 2014 & 2015 & 2016 & 2017 & 2018 & 2019 & & \\
\hline \multirow[t]{9}{*}{ Gan } & 1 & 2005 & 10 & l & l & 1.29 & 1.61 & 0.48 & 0.65 & 0.50 & $\mathrm{~V}$ & $\mathrm{~V}$ \\
\hline & 2 & 2005 & 8 & l & l & 2.40 & 2.0 & 1.80 & 1.60 & 1.0 & $\mathrm{v}$ & $\mathrm{V}$ \\
\hline & 3 & 2005 & 10.7 & / & l & 2.33 & 1.60 & 1.33 & 1.33 & 0.50 & $\mathrm{v}$ & $\mathrm{V}$ \\
\hline & $4^{b}$ & 2006 & 13.3 & l & l & / & 0 & / & I & 100.0 & $\mathrm{x}$ & $\mathrm{x}$ \\
\hline & 5 & 2003 & 2.3 & l & l & 1.54 & 1.15 & 0.77 & 0.46 & 1.0 & $\mathrm{v}$ & $\mathrm{v}$ \\
\hline & 6 & 2003 & 2.4 & l & l & 1.36 & 0.82 & 0.36 & 0.27 & 1.0 & $\mathrm{~V}$ & V \\
\hline & 7 & 2003 & 2.3 & I & I & 1.43 & 1.07 & 1.07 & 0.57 & I & $\mathrm{V}$ & V \\
\hline & 8 & 2003 & 2 & I & I & 1.0 & 0.50 & 0.30 & 0.20 & 0.10 & $\mathrm{~V}$ & $\mathrm{~V}$ \\
\hline & $9^{c}$ & 1997 & 10 & I & I & 50.0 & 12.50 & 7.50 & 5.0 & 0.20 & $\mathrm{v}$ & $\mathrm{V}$ \\
\hline \multirow[t]{6}{*}{ Dayu } & 10 & 1993 & 5.3 & 7.50 & 15.0 & 25.0 & 7.50 & 3.75 & 0.38 & 0.20 & $\mathrm{~V}$ & $\mathrm{~V}$ \\
\hline & 11 & 1993 & 4 & 6.60 & 15.0 & 23.30 & 8.30 & 3.33 & 0.33 & 0.20 & $\mathrm{~V}$ & $\mathrm{~V}$ \\
\hline & 12 & 1993 & 1.7 & 5.0 & 12.50 & 20.8 & 8.33 & 3.0 & 0.25 & 0.10 & $\mathrm{~V}$ & $\mathrm{~V}$ \\
\hline & 13 & 1993 & 2 & 3.12 & 6.25 & 12.50 & 3.12 & 2.50 & 0.25 & 0.10 & $\mathrm{~V}$ & $\mathrm{~V}$ \\
\hline & 14 & 2015 & 20 & I & I & I & I & I & 2.72 & 1.00 & $\mathrm{~V}$ & V \\
\hline & 15 & 2018 & 0.8 & I & I & I & I & I & I & 2.0 & V & $\mathrm{x}$ \\
\hline \multirow[t]{6}{*}{ Chongyi } & 16 & 2009 & 2.7 & 16.80 & 13.70 & 8.95 & 4.21 & 1.05 & 0.42 & 0.14 & $\mathrm{~V}$ & V \\
\hline & 17 & 2005 & 3.3 & 10.0 & 26.60 & 23.30 & 3.00 & 1.00 & 0.40 & 0 & $\mathrm{~V}$ & $\mathrm{~V}$ \\
\hline & 18 & 2009 & 1.3 & I & I & I & 4.50 & 2.50 & 1.20 & 1.0 & $\mathrm{~V}$ & $\mathrm{~V}$ \\
\hline & 19 & 2005 & 0.9 & I & I & I & I & I & I & 0 & $\mathrm{~V}$ & $\mathrm{~V}$ \\
\hline & 20 & 2011 & 1 & 1 & I & I & I & I & I & 2.0 & $\mathrm{~V}$ & $\mathrm{~V}$ \\
\hline & 21 & 2013 & 8 & I & I & 1 & 0.45 & 1.32 & 0.57 & 0.40 & $\mathrm{~V}$ & $\mathrm{~V}$ \\
\hline \multirow[t]{6}{*}{ Xinfeng } & 22 & 2014 & 10 & I & I & I & 3.0 & 3.0 & 3.0 & 1.30 & $\mathrm{~V}$ & $\mathrm{~V}$ \\
\hline & 23 & 2015 & 6.7 & I & I & I & I & I & I & 0.67 & V & $\mathrm{V}$ \\
\hline & 24 & 2015 & 6 & I & I & 1 & 1 & I & I & 3.0 & $\mathrm{~V}$ & $\mathrm{~V}$ \\
\hline & 25 & 2015 & 3.3 & I & I & I & I & I & I & 3.75 & $\mathrm{~V}$ & V \\
\hline & 26 & 2014 & 8 & I & I & I & I & I & 1 & 0.00 & $\mathrm{~V}$ & $\mathrm{~V}$ \\
\hline & 27 & 2016 & 4.7 & 1 & I & 1 & I & I & I & 0.71 & $\mathrm{~V}$ & $\mathrm{~V}$ \\
\hline \multirow[t]{4}{*}{ Yudu } & 28 & 2005 & 20 & I & I & 1 & I & I & 11.10 & 3.46 & $\mathrm{~V}$ & $\mathrm{~V}$ \\
\hline & $29^{d}$ & 2005 & 36.7 & I & I & I & I & I & 75.00 & 24.10 & $\mathrm{X}$ & $\mathrm{X}$ \\
\hline & 30 & 2012 & 14.7 & 0.11 & 0.21 & 0.14 & 4.28 & 2.20 & 2.40 & 3.50 & $\mathrm{~V}$ & $\mathrm{~V}$ \\
\hline & 31 & 2005 & 50 & I & I & I & 3.04 & 6.73 & 1.92 & 1.0 & $\mathrm{~V}$ & $\mathrm{X}$ \\
\hline \multirow[t]{4}{*}{ Ruijin } & 32 & 2005 & 400 & I & I & I & I & / & I & 13.73 & $\mathrm{x}$ & $\mathrm{X}$ \\
\hline & 33 & 2003 & 0.4 & I & I & 1 & 1 & I & I & 2.00 & $\mathrm{~V}$ & $\mathrm{X}$ \\
\hline & 34 & 2003 & 20 & I & I & I & I & 2.00 & 4.76 & 2.14 & $\mathrm{~V}$ & $\mathrm{X}$ \\
\hline & 35 & 2000 & 80 & I & 1 & 1 & I & 3.13 & 2.50 & 2.88 & $\mathrm{~V}$ & $\mathrm{~V}$ \\
\hline \multirow[t]{2}{*}{ Xingguo } & 36 & 2010 & 8 & 1 & I & 1 & I & I & I & 0.13 & $\mathrm{~V}$ & $\mathrm{~V}$ \\
\hline & 37 & 2000 & 15.3 & 1 & I & 1 & I & I & 3.33 & 2.45 & $\mathrm{~V}$ & $\mathrm{~V}$ \\
\hline
\end{tabular}

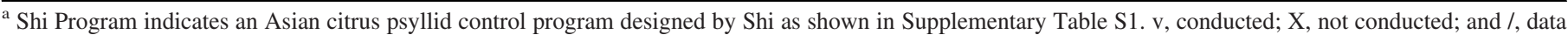
not available.

${ }^{\mathrm{b}}$ HLB was first observed in 2017.

c The three-pronged program was not conducted before 2015 .

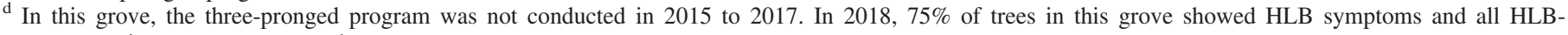
symptomatic trees were removed.

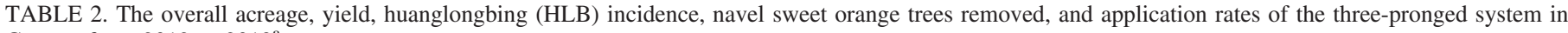
Gannan from 2012 to $2019^{\mathrm{a}}$

\begin{tabular}{|c|c|c|c|c|c|c|c|c|}
\hline \multirow[b]{2}{*}{ Year } & \multirow[b]{2}{*}{$\begin{array}{l}\text { Acreage } \\
\text { (Kha) }\end{array}$} & \multirow[b]{2}{*}{$\begin{array}{l}\text { Total yield } \\
\text { (million tons) }\end{array}$} & \multirow[b]{2}{*}{$\begin{array}{l}\text { HLB-symptomatic } \\
\text { trees removed (million) }\end{array}$} & \multirow[b]{2}{*}{$\begin{array}{l}\text { HLB diseased } \\
\text { trees (million) }\end{array}$} & \multirow[b]{2}{*}{$\begin{array}{c}\text { HLB } \\
\text { incidence }(\%)\end{array}$} & \multicolumn{3}{|c|}{ Application rate } \\
\hline & & & & & & $\begin{array}{l}\text { Psyllid } \\
\text { control }\end{array}$ & $\begin{array}{l}\text { HLB-free } \\
\text { replantation }\end{array}$ & $\begin{array}{c}\text { Removal of } \\
\text { HLB-diseased trees }\end{array}$ \\
\hline 2012 & 118.75 & 1.25 & 1.07 & 1.62 & NA & NA & NA & $66.3 \%$ \\
\hline 2013 & 115.95 & 1.50 & 10.69 & 10.69 & 10.82 & NA & NA & $100 \%$ \\
\hline 2014 & 112.24 & 1.22 & 18.26 & 18.26 & 19.71 & $100 \%$ & $100 \%$ & $100 \%$ \\
\hline 2015 & 104.51 & 1.28 & 6.80 & 6.80 & 7.85 & $100 \%$ & $100 \%$ & $100 \%$ \\
\hline 2016 & 103.23 & 1.08 & 5.71 & 5.71 & 7.21 & $100 \%$ & $100 \%$ & $100 \%$ \\
\hline 2017 & 102.89 & 1.24 & 3.27 & 3.31 & 4.62 & $100 \%$ & $100 \%$ & $99.0 \%$ \\
\hline 2018 & 104.22 & 1.17 & 3.07 & 3.19 & 4.36 & $100 \%$ & $100 \%$ & $96.3 \%$ \\
\hline 2019 & 108.7 & 1.25 & 2.74 & 2.83 & 3.86 & $100 \%$ & $100 \%$ & $96.6 \%$ \\
\hline
\end{tabular}

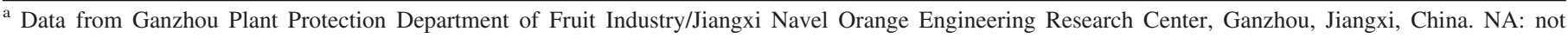
available. 
tons in 2012 to 1.08 million tons in 2016, the lowest amount, but it increased to 1.25 million tons in 2019 (Table 2).

HLB control effect in groves using a representative insecticide program for ACP control in Gannan. We also investigated 30 groves that conducted an ACP control program (Shi Program, Supplementary Table S1; Table 1) in addition to tree removal and replacement with HLB-free trees, considered as part of the region-wide comprehensive HLB management program. Among the seven groves with data from 2013 to 2019, the HLB incidence peaked in 2015 for four groves (12.5 to 25\%), one grove peaked in 2013, another peaked in 2014, and a third peaked in 2016. After this, HLB incidence gradually decreased afterward to 0.1 to $3.5 \%$ in 2019 (Table 1). The other 23 groves under the Shi Program also showed a similar trend (Table 1). Four groves that conducted comprehensive HLB management but with different ACP control programs showed a similar trend. However, the HLB incidence for three groves that did not conduct comprehensive HLB management was $13.73,75$, and $100 \%$ in 2018 or 2019 , much higher than for the 34 groves under the comprehensive HLB control program (Table 1).

Effects of the three-pronged system on HLB control in the São Paulo and Triângulo/Sudoeste Mineiro citrus belt. A comprehensive, three-pronged system was conducted in the São Paulo and Triângulo/Sudoeste Mineiro citrus belt in Brazil in 2005 to 2010 (Table 3) but with reduced inoculum removal after 2010. Before 2010 , all infected trees identified were removed annually; this proportion fell to $66.27,51.68,11.02,11.38,9.66$, and $9.07 \%$ in 2011, 2012, 2015, 2016, 2017, and 2018, respectively (Table 3). Consequently, overall HLB incidence ranged from 0.22 to $1.89 \%$ in 2005 to 2010, but it increased to $3.80 \%$ in 2011 and $19.02 \%$ in 2019.

Modeling analyses based on data from China and Brazil. With data from both China (Table 2) and Brazil (Table 3), we took into account the complexity of the model and limitations of the data and chose a model with one lagged dependent variable, which eliminated autocorrelation in the error term. Here, we estimated the model as follows:

$$
\begin{gathered}
y_{t}=18.2119+0.3150 y_{t-1}-0.1332 x_{1, t}-4.4131 x_{2, t}+\varepsilon_{t} \\
\varepsilon_{t} \sim \operatorname{NID}\left(0,3.8917^{2}\right)
\end{gathered}
$$

where $y_{t}$ is the disease incidence of year $\mathrm{t}, x_{1, t}$ represents component 3 (removal of diseased trees) of year $t$, and $x_{2, t}$ is the dummy variable representing Brazil or China. Using this model, we concluded that when all HLB-symptomatic trees were removed from groves, the HLB disease incidence will decrease by a linear factor of $13.32 \%$. Disease incidence $y_{t}$ also depends on the incidence in the previous year with the relationship described. It was predicted that when all HLB-symptomatic trees in a given grove were removed each year in the São Paulo and Triângulo/Sudoeste Mineiro citrus belt or in China $\left(x_{\downarrow}(2, t)=1\right)$, disease incidence would be controlled to a level of less than $1 \%$ or reaching near-complete control.

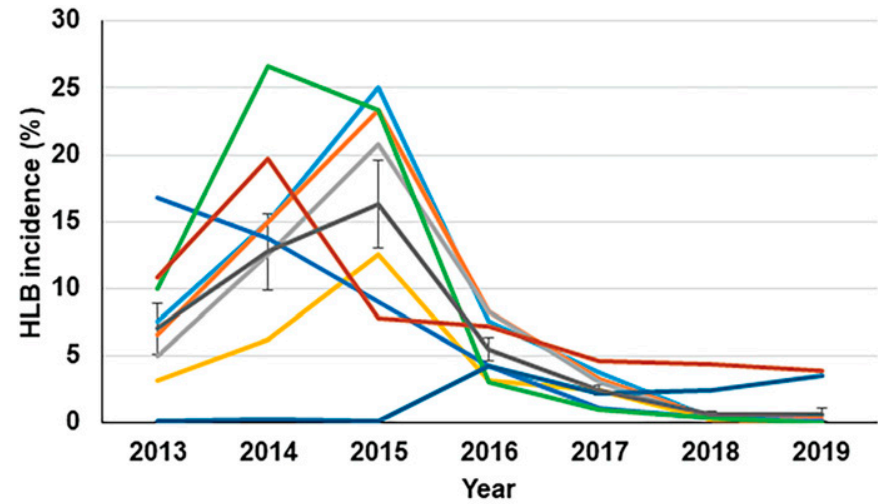

Fig. 1. Huanglongbing (HLB) incidence in citrus groves in Gannan, Jiangxi, China where the three-pronged HLB management program was conducted from 2013 to 2019. The overall HLB incidence in citrus groves in Gannan was shown. The HLB incidence for seven selected groves is also shown. The average HLB incidence for the seven selected groves is shown. Error bar indicates standard error. The overall HLB disease incidence in Gannan was assessed for every tree in all citrus groves by visual observation of typical HLB symptoms in October to December between 2013 and 2019. For the selected groves, the HLB incidence data in 2013 to 2018 were based on visual observation of HLB symptoms for all trees in each grove, whereas the HLB incidence in 2019 was based on visual investigation of approximately $20 \%$ trees of selected groves in October to December, followed by PCR confirmation of 10 symptomatic trees per grove.

TABLE 3. The overall acreage, yield, huanglongbing (HLB) incidence, HLB-symptomatic citrus trees removed, and application rates of the three-pronged system in the São Paulo and Triângulo/Sudoeste Mineiro citrus belt from 2005 to 2019

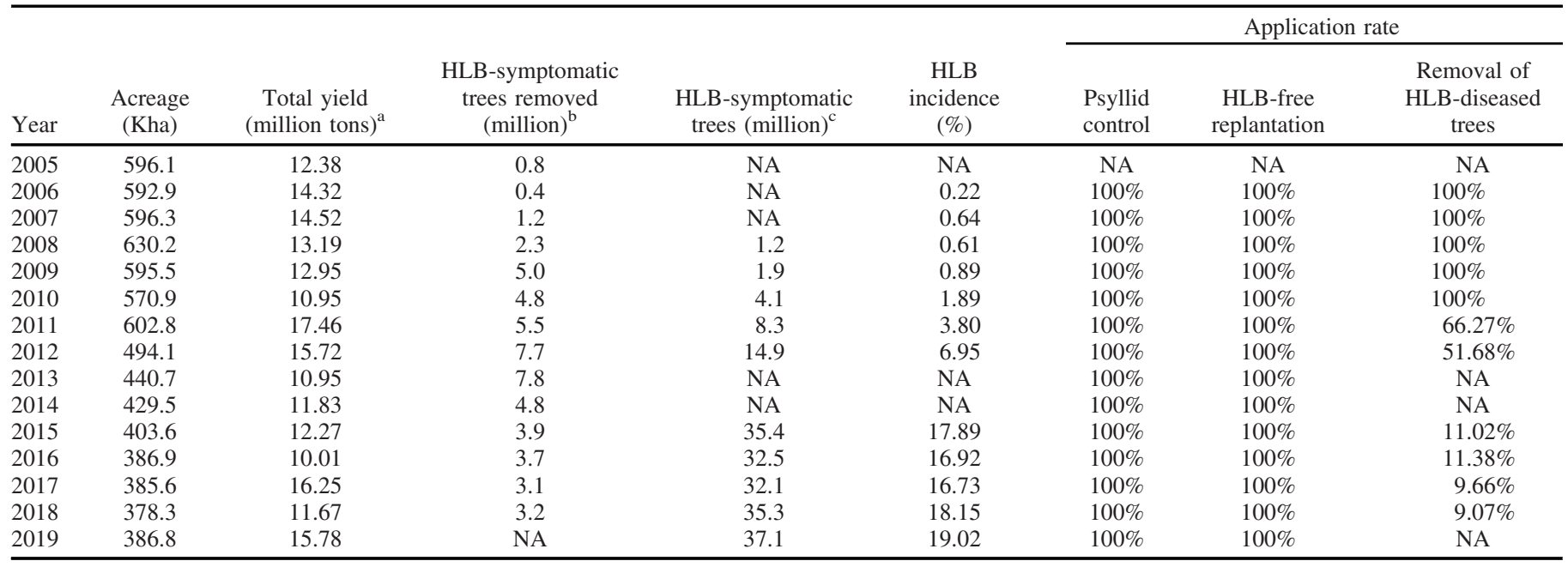

${ }^{a}$ Data from Brazilian Association of Citrus Exporters from 2005 to 2014 and from Fundecitrus/PES from 2015 to 2019.

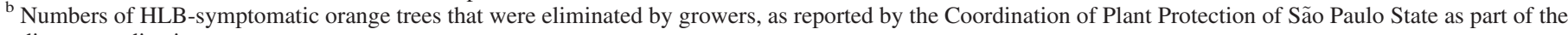
disease eradication program.

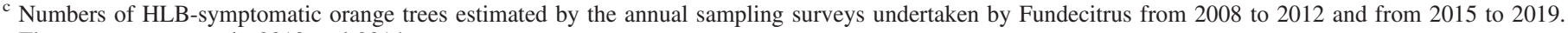
There was no survey in 2013 and 2014. 
We further conducted nonlinear regression analyses based on data from China (Table 2). Here, we constructed the model shown in Figure 2. This model properly describes the progression of HLB incidence in the groves that received comprehensive disease control scheme over time, with effective goodness-of-fit $(F=69.04 ; P=$ $0.0067 ; R^{2}=0.7815 ;$ Fig. 2 ). The annual rate of progression of Las-infected trees in the groves was estimated to be 0.51 year $^{-1}$ (Fig. 2). Based on this model, in the best-case scenario, the comprehensive disease control scheme might lead to low disease incidence $\leq 1 \%$ by 2022 . The results of these nonlinear regression analyses are therefore consistent with those of dynamic linear regression analyses, indicating the robustness of the prediction.

Economic feasibility results and comparison. The whole farm budgeting results show that average net profits per year over 10 years are positive for groves that implemented the comprehensive strategy, indicating that the comprehensive strategy was economically effective. Conversely, groves that did not implement the strategy generated negative net profits, causing financial stress over a 10 -year period. Net profit is defined as sales minus all costs, including removal of HLBdiseased trees (\$0.54 per tree), cultivating young HLB-free trees (\$1.74 per tree), replacing HLB-free trees $(\$ 0.54$ per tree), the Shi Program cost ( $\$ 0.16$ per tree per application), fertilizer ( $\$ 2.89$ per tree), and harvest and maintenance labor ( $\$ 5.07$ per tree). The results showed that groves that adopted the comprehensive strategy generated an average net profit of $\$ 42$ per tree per year. The net profits across groves ranged from $\$ 11$ to $\$ 104$ per tree/year. The recently established groves performed more poorly because the trees had not achieved full productivity. For groves without the comprehensive strategy, the average net profit was $-\$ 0.52$ per tree/year. The $t$ test showed that the difference between profits with and without the strategy was statistically significant, which implies that the three-pronged strategy could generate much greater benefit to growers and should be adopted.

\section{DISCUSSION}

The reduction of HLB incidence from 2013 to 2019 in citrus groves under the comprehensive HLB management program in the Gannan region of China and the economic analyses validated our hypothesis

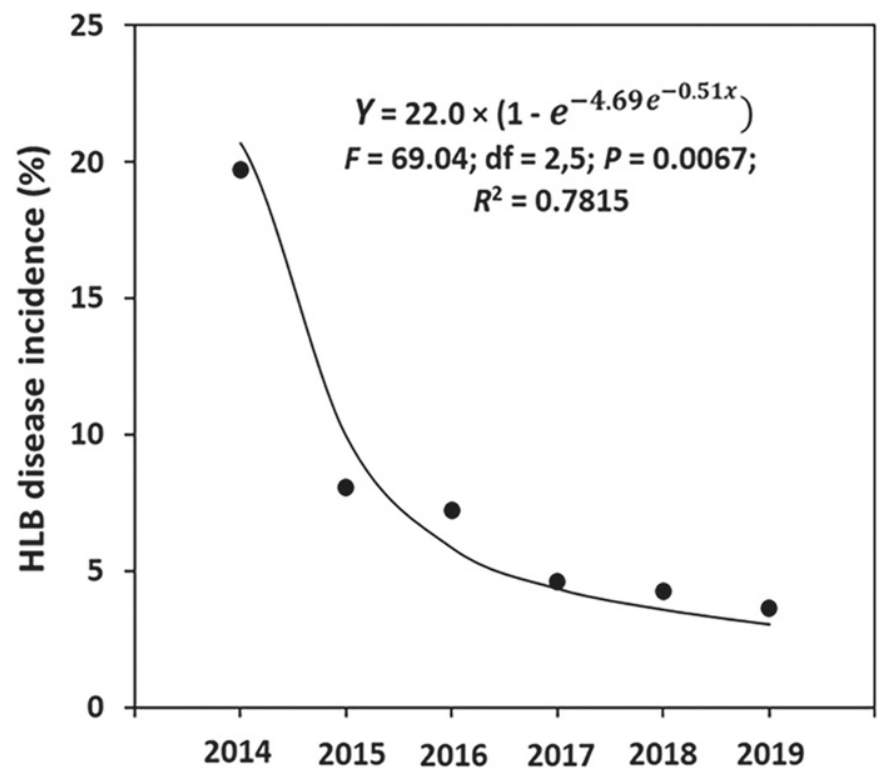

Fig. 2. The progression of huanglongbing (HLB) incidence in citrus groves receiving the comprehensive disease control scheme (three-pronged system) in Gannan, China from 2014 to 2019. Shown are the observed data and fitted curve from nonlinear least squares estimation with Gompertz function, where $Y=$ HLB disease incidence, and $x=$ time (years post-implementation of the comprehensive disease control scheme). that region-wide comprehensive implementation of roguing infected trees, tree replacement, and insecticide applications can successfully control HLB. This program had not eliminated HLB in Gannan by 2019 and had incurred costs in tree removal, tree replacement, and insecticide application. However, the groves that were under the comprehensive management program were making a profit, while the groves that were not following the program were suffering an economic loss. However, it remains unknown whether comprehensive HLB management can be successfully implemented elsewhere due to differences in costs, for example labor costs are much higher in the United States than in China. Detailed economic analyses for each citrus production region are needed.

Comprehensive HLB management, including roguing infected trees, tree replacement, and insecticide application, was conducted in Brazil after the discovery of the disease in 2004 and was continued until 2010. During this period, overall HLB incidence in São Paulo gradually increased but remained at relatively low levels, such as $1.89 \%$ in 2010 . However, it dramatically increased to $17.89 \%$ in 2015 and to $19.02 \%$ in 2019 , as only a subset of the infected trees were removed after 2010 despite the continued rigorous use of insecticides. The data from Brazil serves as an imperfect control for comparison with that in Gannan; both programs were at the regional level, with a comprehensive implementation in Gannan, but a partial implementation (incomplete inoculum removal) in Brazil. The comparison clearly shows the importance of the comprehensive removal of HLBsymptomatic trees for HLB management, which is consistent with the results of small-scale trials (Bassanezi et al. 2013). Our modeling analyses clearly demonstrate the contribution of the complete removal of HLB-symptomatic trees to HLB management. This is consistent with the effects of large-scale implementation of a comprehensive program for HLB control in Gannan. It should be noted that when the comprehensive HLB management program was conducted in Brazil and Gannan, the effects on HLB incidence were different between the two places. One possible explanation for this is that the HLB survey in Gannan covered all trees, while the survey in Brazil was based on sampling. This difference in practice probably determined whether all HLB-diseased trees were identified and removed. Furthermore, a similar program conducted by some citrus growers in Florida serves as imperfect controls for comparison with that in Gannan. The program in Florida was implemented at local or area levels. Local or area-wide implementation of such a program failed to achieve substantial disease reduction (Singerman and Rogers 2020), contrary to the significant HLB control in Gannan. The inefficacy of implementation of such a program at local or area levels probably results from ACP dispersal among groves that nullifies or reduces the effect of psyllid control, inoculum removal, or replanting with HLB-free trees, whereas region-wide comprehensive implementation of such a program likely eliminates ACP dispersal and transmission of CLas across groves. It was reported that ACP can disperse at least $2 \mathrm{~km}$ within 12 days in the absence of severe weather events (Lewis-Rosenblum et al. 2015), and wind-assisted ACP dispersal in Florida ranges from 90 to $145 \mathrm{~km}$ (Gottwald et al. 2007). This comparison further supports the hypothesis that region-wide implementation of roguing infected trees, tree replacement, and insecticide applications can successfully control HLB. It is estimated that nearly all mature, productive trees in Florida citrus groves are currently infected with HLB (Graham et al. 2020). Because state-wide roguing of HLBsymptomatic trees was never conducted, it is apparent from our modeling that disease incidence is likely to increase rapidly.

One argument against the removal of the HLB inoculum is its long incubation period before symptom appearance (Chiyaka et al. 2012; Pandey and Wang 2019). It takes several months to several years for CLas-infected trees to become symptomatic (Gottwald et al. 2007; Shen et al. 2013b; Shimwela et al. 2019). Furthermore, asymptomatic trees are infectious, and citrus psyllids are able to acquire CLas within 10 to 15 days of receiving the bacterial inoculum from an adult psyllid (Lee et al. 2015). However, the continuous and complete removal of HLB-symptomatic trees appears sufficient to reduce 
the rate of appearance of newly infected trees. In addition, asymptomatic trees typically have lower CLas titers in planta than healthy trees (Trivedi et al. 2009; Vasconcelos et al. 2020). Thus, newly infected but asymptomatic trees are less infectious, reducing the ACP transmission of CLas by psyllids. In addition, groves with over $30 \%$ HLB incidence in Gannan were completely removed, which eliminated the inoculum not only from symptomatic but also CLas-positive but asymptomatic trees. Thus, the persistent and comprehensive removal of HLB-symptomatic trees is an important component in a comprehensive strategy to control HLB.

Rigorous psyllid management has been conducted in Florida, Brazil, and Gannan with varying degrees of coordination (Bassanezi et al. 2020; Singerman and Rogers 2020). The importance of psyllid control for successful HLB management has been reported (Bassanezi et al. 2013; Boina and Bloomquist 2015). In all three regions, high populations of ACPs were not observed in groves that were undergoing comprehensive HLB management. One distinctive feature of Gannan that might have affected psyllid behavior and CLas transmission differently from in Brazil and Florida is that there are many mountains that might have limited the movement of ACP between groves in Gannan. However, it seems unlikely that the landscape in Gannan is the main driver of lower disease incidence in this region because HLB incidence reached 13.73 to $100 \%$ in groves that were not isolated from other groves and did not have comprehensive disease management, without psyllid control or removal of HLBsymptomatic trees. It is important to note that few citrus groves in Gannan did not conduct comprehensive management, so Gannan has been employing a nearly complete, comprehensive, region-wide implementation of roguing, tree replacement, and psyllid control. Conversely, it has been demonstrated that HLB control is ineffective when only a few individual groves practice comprehensive psyllid control and the removal of HLB-symptomatic trees (Bassanezi et al. 2013). We can also exclude the supposition that the reduction of the HLB incidence resulted from the climate because the climate is suitable for both ACPs and CLas in Gannan.

Gannan utilized an innovative approach that makes it more practical to replace HLB-diseased trees. Although HLB-free trees are used for replacement in Florida and São Paulo, those in Gannan are grown in psyllid-proof screenhouses to a large size in order to produce backup trees to replace the diseased trees that are removed. This innovative replacement approach allows the citrus groves to suffer a low incidence of HLB and maintain a relatively high productivity by reducing the time needed for replacement trees to come into production. Because the juvenile stage for most commercial citrus varieties lasts 2 to 3 years, the use of older replacement trees allows production soon after planting. This innovative approach results in better economic returns than replacement with younger trees and enables both higher fruit yield and quality while maintaining lower HLB incidence, which allows the more costly HLB management system to be economically viable. In addition, replacement with 2- to 3 -year-old trees reduces number of flushes with younger trees. Young flushes are key for the psyllid life cycle and CLas transmission (Hall et al. 2016).

Taken together, we have demonstrated the effectiveness of regionwide comprehensive implementation of roguing infected trees, tree replacement, and insecticide application to control HLB. The key for the three-pronged program to successfully control HLB is the large scale (region-wide) and comprehensiveness in implementation. Due to the nature of the study, we were unable to determine the contribution of individual components to control HLB except that of inoculum removal. However, this study and previous work suggest that all three components of the comprehensive HLB management program contribute to successful management of HLB while maintaining the economic viability of citrus production. Furthermore, groves that implemented this system generated a sustainable profit; those that did not experienced financial losses. The implementation of this comprehensive HLB management scheme in Gannan (2013 to 2019) and in São Paulo (2004 to 2010) indicates that it is feasible to maintain citrus production despite the presence of a devastating endemic pathogen. It also serves as a valuable example for the management of other endemic plant diseases.

\section{ACKNOWLEDGMENTS}

We thank Steven E. Lindow for his critical reading and help with the manuscript.

\section{LITERATURE CITED}

Akula, N., Zheng, H., Han, F. Q., and Wang, N. 2011. Discovery of novel SecA inhibitors of Candidatus Liberibacter asiaticus by structure based design. Bioorg. Med. Chem. Lett. 21:4183-4188.

Bassanezi, R., Montesino, L., Gimenes-Fernandes, N., Yamamoto, P., Gottwald, T., Amorim, L., and Filho, A. 2013. Efficacy of area-wide inoculum reduction and vector control on temporal progress of Huanglongbing in young sweet orange plantings. Plant Dis. 97:789-796.

Bassanezi, R. B., Lopes, S. A., de Miranda, M. P., Wulff, N. A., Volpe, H. X. L., and Ayres, A. J. 2020. Overview of citrus huanglongbing spread and management strategies in Brazil. Trop. Plant Pathol. 45:251-264.

Boina, D. R., and Bloomquist, J. R. 2015. Chemical control of the Asian citrus psyllid and of huanglongbing disease in citrus. Pest Manag. Sci. 71:808-823.

Boina, D. R., Rogers, M. E., Wang, N., and Stelinski, L. L. 2010. Effect of pyriproxyfen, a juvenile hormone mimic, on egg hatch, nymph development, adult emergence and reproduction of the Asian citrus psyllid, Diaphorina citri Kuwayama. Pest Manag. Sci. 66:349-357.

Bové, J. M. 2006. Huanglongbing: A destructive, newly-emerging, century-old disease of citrus. J. Plant Pathol. 88:7-37.

Canales, E., Coll, Y., Hernández, I., Portieles, R., Rodríguez García, M., López, Y., Aranguren, M., Alonso, E., Delgado, R., Luis, M., Batista, L., Paredes, C., Rodríguez, M., Pujol, M., Ochagavia, M. E., Falcón, V., Terauchi, R., Matsumura, H., Ayra-Pardo, C., Llauger, R., Pérez, M. C., Núñez, M., Borrusch, M. S., Walton, J. D., Silva, Y., Pimentel, E., Borroto, C., and Borrás-Hidalgo, O. 2016. 'Candidatus Liberibacter asiaticus', causal agent of citrus Huanglongbing, is reduced by treatment with brassinosteroids. PLoS One 11:e0146223.

Chiyaka, C., Singer, B. H., Halbert, S. E., Morris, J. G., and van Bruggen, A. H. 2012. Modeling huanglongbing transmission within a citrus tree. Proc. Natl. Acad. Sci. USA 109:12213-12218.

Deng, H., Achor, D., Exteberria, E., Yu, Q., Du, D., Stanton, D., Liang, G., and Gmitter, F. G. 2019. Phloem regeneration is a mechanism for Huanglongbing-tolerance of "Bearss" lemon and "LB8-9" Sugar Belle mandarin. Sugar Belle. Front. Plant Sci. 10:277.

Folimonova, S. Y., Robertson, C. J., Garnsey, S. M., Gowda, S., and Dawson, W. O. 2009. Examination of the responses of different genotypes of citrus to Huanglongbing (citrus greening) under different conditions. Phytopathology 99:1346-1354

Gottwald, T., da Graça, J., and Renato, B. 2007. Citrus huanglongbing: The pathogen and its impact. Plant Health Prog. 8:1.

Gottwald, T., Poole, G., McCollum, T., Hall, D., Hartung, J., Bai, J., Luo, W., Posny, D., Duan, Y. P., Taylor, E., da Graça, J., Polek, M., Louws, F., and Schneider, W. 2020. Canine olfactory detection of a vectored phytobacterial pathogen, Liberibacter asiaticus, and integration with disease control. Proc. Natl. Acad. Sci. USA 117:3492-3501.

Gottwald, T. R. 2010. Current epidemiological understanding of citrus Huanglongbing. Annu. Rev. Phytopathol. 48:119-139.

Gottwald, T. R., Graham, J. H., Irey, M. S., McCollum, T. G., and Wood, B. W. 2012. Inconsequential effect of nutritional treatments on huanglongbing control, fruit quality, bacterial titer and disease progress. Crop Prot. 36: 73-82.

Gottwald, T. R., and McCollum, T. G. 2017. Huanglongbing solutions and the need for anti-conventional thought. J. Citrus Pathol. 4:36952.

Graham, J., Gottwald, T., and Setamou, M. 2020. Status of Huanglongbing (HLB) outbreaks in Florida, California and Texas. Trop. Plant Pathol. 45: 265-278.

Halbert, S. E. 2005. The discovery of huanglongbing in Florida. Pages H-3 in 2nd Intl. Citrus Canker and Huanglongbing Research Workshop, Orlando, FL.

Hall, D. G., Albrecht, U., and Bowman, K. D. 2016. Transmission Rates of ' $\mathrm{Ca}$. Liberibacter asiaticus' by Asian citrus psyllid are enhanced by the presence and developmental stage of citrus flush. J. Econ. Entomol. 109:558-563.

Hodges, A. W., Rahmani, M., Stevens, T. J., and Spreen, T. H. 2014. Economic Impacts of the Florida Citrus Industry in 2012-13. University of Florida, Gainesville. 
Hu, J., and Wang, N. 2016. Evaluation of the spatiotemporal dynamics of oxytetracycline and its control effect against citrus huanglongbing via trunk injection. Phytopathology 106:1495-1503.

Hussain, S., Rao, M. J., Anjum, M. A., Ejaz, S., Umar, U. U., Ali, M. A., Khalid, M. F., Sohail, M., Ercisli, S., Zia-Ul-Haq, M., Ahmad, S., and Naqvi, S. A. H. 2019. Effect of different combinations of antibiotics on fruit quality and antioxidant defense system in Huanglongbing infected Kinnow orchards. AMB Express 9:147.

Jia, H., Orbović, V., and Wang, N. 2019. CRISPR-LbCas12a-mediated modification of citrus. Plant Biotechnol. J. 17:1928-1937.

Jia, H., and Wang, N. 2014. Xcc-facilitated agroinfiltration of citrus leaves: A tool for rapid functional analysis of transgenes in citrus leaves. Plant Cell Rep. 33:1993-2001.

Jia, H., and Wang, N. 2020. Generation of homozygous canker-resistant citrus in the T0 generation using CRISPR-SpCas9p. Plant Biotechnol. J. 18:19901992.

Jia, H., Xu, J., Orbović, V., Zhang, Y., and Wang, N. 2017. Editing citrus genome via SaCas9/sgRNA system. Front. Plant Sci. 8:2135.

Kim, J. S., and Wang, N. 2009. Characterization of copy numbers of 16 S rDNA and 16S rRNA of Candidatus Liberibacter asiaticus and the implication in detection in planta using quantitative PCR. BMC Res. Notes 2:37.

Lee, J. A., Halbert, S. E., Dawson, W. O., Robertson, C. J., Keesling, J. E., and Singer, B. H. 2015. Asymptomatic spread of huanglongbing and implications for disease control. Proc. Natl. Acad. Sci. USA 112:7605-7610.

Lewis-Rosenblum, H., Martini, X., Tiwari, S., and Stelinski, L. L. 2015. Seasonal movement patterns and long-range dispersal of Asian citrus psyllid in Florida citrus. J. Econ. Entomol. 108:3-10.

Li, J., Kolbasov, V., Lee, D., Pang, Z., Huang, Y., Collins, N., and Wang, N. 2021. Residue dynamics of streptomycin in citrus delivered by foliar spray and trunk injection and effect on 'Candidatus Liberibacter asiaticus' titer. Phytopathology. doi: 10.1094/PHYTO-09-20-0427-R.

Li, J., Li, L., Pang, Z., Kolbasov, V. G., Ehsani, R., Carter, E. W., and Wang, N. 2019a. Developing citrus Huanglongbing (HLB) management strategies based on the severity of symptoms in HLB-endemic citrus-producing regions. Phytopathology 109:582-592.

Li, J., Pang, Z., Duan, S., Lee, D., Kolbasov, V., and Wang, N. 2019b. The in planta effective concentration of oxytetracycline against Candidatus Liberibacter asiaticus for suppression of citrus Huanglongbing. Phytopathology 109:2046-2054.

Li, J., Pang, Z., Trivedi, P., Zhou, X., Ying, X., Jia, H., and Wang, N. 2017. 'Candidatus Liberibacter asiaticus' encodes a functional salicylic acid (SA) hydroxylase that degrades SA to suppress plant defenses. Mol. Plant-Microbe Interact. 30:620-630.

Li, J., Trivedi, P., and Wang, N. 2016. Field evaluation of plant defense inducers for the control of citrus Huanglongbing. Phytopathology 106:3746.

Li, S., Wu, F., Duan, Y., Singerman, A., and Guan, Z. 2020. Citrus greening: Management strategies and their economic impact. HortScience 55:604-612.

McCollum, G., Hilf, M., Irey, M., Luo, W., and Gottwald, T. 2016. Susceptibility of sixteen citrus genotypes to 'Candidatus Liberibacter asiaticus'. Plant Dis. 100:1080-1086.

Pandey, S. S., and Wang, N. 2019. Targeted early detection of citrus HLB causal agent 'Candidatus Liberibacter asiaticus' before symptom expression. Phytopathology 109:952-959.

Pang, Z., Zhang, L., Coaker, G. L., Ma, W., He, S. Y., and Wang, N. 2020. Citrus CsACD2 is a target of Candidatus Liberibacter asiaticus in Huanglongbing disease. Plant Physiol. 184:792-805.

Shen, W., Cevallos-Cevallos, J. M., Nunes da Rocha, U., Stansly, P. A., Roberts, P. D., and van Bruggen, A. H. C. 2013a. Relation between plant nutrition, hormones, insecticide applications, bacterial endophytes, and Candidatus Liberibacter $\mathrm{Ct}$ values in citrus trees infected with huanglongbing. Eur. J. Plant Pathol. 137:727-742.

Shen, W., Halbert, S. E., Dickstein, E., Manjunath, K. L., Shimwela, M. M., and van Bruggen, A. H. C. 2013b. Occurrence and in-grove distribution of citrus huanglongbing in north central Florida. J. Plant Pathol. 95:361-371.

Shimwela, M. M., Halbert, S. E., Keremane, M. L., Mears, P., Singer, B. H., Lee, W. S., Jones, J. B., Ploetz, R. C., and van Bruggen, A. H. C. 2019. In-grove spatiotemporal spread of citrus huanglongbing and its psyllid vector in relation to weather. Phytopathology 109:418-427.

Shimwela, M. M., Narouei Khandan, H. A., Halbert, S. E., Keremane, M. L., Minsavage, G. V., Timilsina, S., Massawe, D. P., Jones, J. B., and van Bruggen, A. H. C. 2016. First occurrence of Diaphorina citri in East Africa, characterization of the $\mathrm{Ca}$. Liberibacter species causing huanglongbing (HLB) in Tanzania, and potential further spread of D. citri and HLB in Africa and Europe. Eur. J. Plant Pathol. 146:349-368.

Shimwela, M. M., Schubert, T., Albritton, M., Halbert, S. E., Jones, D. J., Sun, X., Roberts, P. D., Singer, B. H., Lee, W. S., Jones, J. B., Ploetz, R. C., and van Bruggen, A. H. C. 2018. Regional spatial-temporal spread of citrus huanglongbing is affected by rain in Florida. Phytopathology 108:14201428 .

Singerman, A., and Rogers, M. E. 2020. The economic challenges of dealing with citrus greening: The case of Florida. J. Integr. Pest Manag. 11:3.

Stansly, P. A., Arevalo, H. A., Qureshi, J. A., Jones, M. M., Hendricks, K., Roberts, P. D., and Roka, F. M. 2014. Vector control and foliar nutrition to maintain economic sustainability of bearing citrus in Florida groves affected by huanglongbing. Pest Manag. Sci. 70:415-426.

Teixeira, D. D. C., Saillard, C., Eveillard, S., Danet, J. L., Costa, P. I. D., Ayres, A. J., and Bové, J. 2005 'Candidatus Liberibacter americanus', associated with citrus huanglongbing (greening disease) in São Paulo State, Brazil. Int. J. Syst. Evol. Microbiol. 55:1857-1862.

Thapa, S. P., De Francesco, A., Trinh, J., Gurung, F. B., Pang, Z., Vidalakis, G., Wang, N., Ancona, V., Ma, W., and Coaker, G. 2020. Genome-wide analyses of Liberibacter species provides insights into evolution, phylogenetic relationships, and virulence factors. Mol. Plant Pathol. 21:716-731.

Trivedi, P., Sagaram, U. S., Kim, J., Brlansky, R. H., Rogers, M. E., Stelinski, L. L., Oswalt, C., and Wang, N. 2009. Quantification of viable Candidatus Liberibacter asiaticus in hosts using quantitative PCR with the aid of ethidium monoazide (EMA). Eur. J. Plant Pathol. 124:553-563.

Vasconcelos, F. N. C., Li, J., Pang, Z., Vincent, C., and Wang, N. 2020. Census of 'Candidatus Liberibacter asiaticus' population inside the phloem of citrus trees. Phytopathology.

Wang, N. 2020. A perspective of citrus Huanglongbing in the context of the Mediterranean Basin. J. Plant Pathol. 102:635-640.

Wang, N., Pierson, E. A., Setubal, J. C., Xu, J., Levy, J. G., Zhang, Y., Li, J., Rangel, L. T., and Martins, J. 2017a. The Candidatus Liberibacter-host interface: Insights into pathogenesis mechanisms and disease control. Annu. Rev. Phytopathol. 55:451-482.

Wang, N., Stelinski, L. L., Pelz-Stelinski, K. S., Graham, J. H., and Zhang, Y. 2017b. Tale of the Huanglongbing disease pyramid in the context of the citrus microbiome. Phytopathology 107:380-387.

Wang, Z., Yin, Y., Hu, H., Yuan, Q., Peng, G., and Xia, Y. 2006. Development and application of molecular-based diagnosis for 'Candidatus Liberibacter asiaticus', the causal pathogen of citrus huanglongbing. Plant Pathol. 55: 630-638

Zheng, Z., Chen, J., and Deng, X. 2018. Historical perspectives, management, and current research of citrus HLB in Guangdong Province of China, where the disease has been endemic for over a hundred years. Phytopathology 108: 1224-1236. 